\title{
Verteporfin-photodynamic therapy is effective on gastric cancer cells
}

\author{
YUKARI MAE, TSUTOMU KANDA, TAKAAKI SUGIHARA, TOMOAKI TAKATA, HIDEHITO KINOSHITA, \\ TAKUKI SAKAGUCHI, TAKASHI HASEGAWA, RYOHEI TARUMOTO, MIRAI EDANO, HIROKI KURUMI, \\ YUICHIRO IKEBUCHI, KOICHIRO KAWAGUCHI and HAJIME ISOMOTO
}

\author{
Division of Medicine and Clinical Science, Department of Multidisciplinary Internal Medicine, \\ Faculty of Medicine, Tottori University, Yonago, Tottori 683-8504, Japan
}

Received April 22, 2019; Accepted May 15, 2020

DOI: $10.3892 / \mathrm{mco} .2020 .2081$

\begin{abstract}
Photodynamic therapy(PDT) induces photochemical reactions, resulting in the destruction of tumor cells via singlet (S1) oxygen production. This cellular destruction occurs specifically in tumor cells, following selective accumulation of a photosensitizer and its excitation by a specific wavelength. Verteporfin (VP) is a second-generation photosensitizer that is currently being used worldwide in PDT to treat age-related macular degeneration. In addition, clinical trials with VP-PDT demonstrated anti-tumor efficacy and overall safety when used to treat locally advanced pancreatic cancer. In the present study, we examined the anti-tumor effect of VP-PDT on gastric cancer (GC) cell lines in vitro to conduct an initial assessment of its potential clinical applicability to this specific type of cancer. We evaluated the viability of MKN45 and MKN74 cancer cell lines after VP-PDT exposure and calculated the half maximal effective concentration $\left(\mathrm{EC}_{50}\right)$ values for VP. Apoptosis in VP-PDT-exposed GC cells was observed. Furthermore, the $\mathrm{EC}_{50}$ values for a 30-min treatment with VP $\left(2.5 \mathrm{~J} / \mathrm{cm}^{2}\right.$ of $660 \mathrm{~nm}$ LED light) were 0.61 and $1.21 \mu \mathrm{M}$ for MKN45 and MKN74, respectively. When VP treatment times were increased, the $\mathrm{EC}_{50}$ values decreased. In conclusion, VP-PDT may be developed as an effective treatment for GC.
\end{abstract}

Correspondence to: Dr Hajime Isomoto, Division of Medicine and Clinical Science, Department of Multidisciplinary Internal Medicine, Faculty of Medicine, Tottori University, 36-1 Nishi-cho, Yonago, Tottori 683-8504, Japan

E-mail: isomoto@tottori-u.ac.jp

Abbreviations: EDL, excimer dye laser; ESD, endoscopic submucosal dissection; GC, gastric cancer; OPO, optical parameter oscillator; PDT, photodynamic therapy; PS, porfimer sodium; S0, ground state; S1, singlet state; S3, triplet state; TS, talaporfin sodium; VP, verteporfin; YAG, yttrium aluminum garnet

Key words: photodynamic therapy, verteporfin, gastric cancer cell lines, singlet oxygen, mitochondria

\section{Introduction}

Gastric cancer (GC) is the third most common cause of cancer-related deaths worldwide (1). Differentiated-type early-stage GC, with a low risk of lymph node metastasis, can be successfully treated using local endoscopic procedures, such as endoscopic submucosal dissection (ESD) (2) or PDT (3). ESD has already been suggested as a treatment for intramucosal and superficial submucosal GC, whereas PDT is the preferred strategy to treat submucosal GC without lymph (and other distant) metastases. Alternatively, PDT can be used as a palliative therapy for advanced and localized GC in order to reduce the tumor burden (4).

PDT elicits localized cell death in tumors, using a combination of light, a photosensitizer, and tissue oxygen (5). In theory, because photosensitizers specifically accumulate in tumors, there should not be any off-target effects of PDT, allowing for the selective treatment of tumor lesions. When a photosensitizer is irradiated with light of a specific wavelength, it is excited from a ground state (S0) to an S1 state. Subsequently, due to intersystem crossing, the photosensitizer reaches a triplet state (S3) then returns to S0 while transferring energy to oxygen. The oxygen molecule that receives the energy subsequently reaches S1 (singlet oxygen), thus destroying cancer cells (5).

PDT has several advantages over more invasive procedures such as ESD, including a reduced risk of bleeding, and can be safely performed in conjunction with the administration of antiplatelet medication (6). In Japan, the first-generation photosensitizer (porfimer sodium, PS) and second-generation photosensitizers [talaporfin sodium (TS) and verteporfin (VP)] have already obtained regulatory approval for use with PDT. Using PDT to treat early-stage GC is approved only when combining PS with excimer dye laser (EDL) or Yttrium Aluminum Garnet (YAG) optical parameter oscillator (OPO) lasers (YAG-OPO: Ishikawajima-Harima Heavy Industries Co., Ltd.: IHI). However, because EDL and YAG OPO devices are very expensive, their production has been stopped (3). Furthermore, in order to avoid sunlight sensitivity after treatment, a light-blocking period of four weeks or more is required with this approach. Even the second-generation photosensitizer TS requires a continuous light-blocking period of at least two 
weeks. By contrast, VP-based PDT requires a light-blocking period of no more than two days, which is considerably shorter than the clinically available photosensitizers. As the effectiveness and safety of VP are well established, it is widely used in PDT to treat age-related macular degeneration $(7,8)$. Furthermore, the absorption peak of VP is $689 \mathrm{~nm}$, whereas the absorption peaks of PS and TS are 630 and $664 \mathrm{~nm}$, respectively. The longer wavelength light $(689 \mathrm{~nm})$ penetrates deeper and can pass through the submucosal layer into the mucosal lamina propria, resulting in effectiveness even for invasive GC. In 2014, a phase I/II study to treat locally advanced pancreatic cancer with VP-PDT was conducted, and the safety of the approach was confirmed (8). The notable efficacy of VP-PDT, in combination with paclitaxel, on GC cells (NCI-N87 derived from liver metastases) was demonstrated previously (9); however, the particular effect of VP-PDT on GC cells has yet to be adequately elucidated.

The aim of the present study was to evaluate the effect of VP-PDT on two different superficial submucosal GC cell lines, MKN45 and MKN74, which were derived from undifferentiated and well-differentiated adenocarcinoma, respectively. The two cell types were exposed individually or in combination to VP-PDT. VP-PDT was effective on these cells using a combination of light and a photosensitizer. Through this study, we pave the way for future clinical applications of VP-PDT for GC (with nominal risks of lymph node and distant metastasis), such as intramucosal GC and GC with superficial invasion into the muscular propriae (common in aged individuals).

\section{Materials and methods}

Cell lines. Human gastric cancer cell lines and cultures, MKN45-Luc and MKN74/CMV-Luc cells, were obtained from the JCRB cell bank. Cells were cultured in a humidified incubator $\left(5 \% \mathrm{CO}_{2}, 37^{\circ} \mathrm{C}\right)$ in RPMI-1640 medium without antibiotics, supplemented with $10 \%$ fetal bovine serum and $1 \%$ L-glutamine solution. Immortalized human pancreatic duct epithelial cell (T0005; Applied Biological Materials Inc.) and was cultured in Prigrow I medium and D-MEM/Ham's F-12 medium, respectively. Both media were supplemented with $20 \%$ fetal bovine serum without antibiotics. A normal rat gastric epithelial cell line; RGM-1 (a gift from Dr Matsui; University of Tsukuba) (10) was cultured in D-MEM/Ham's F-12 medium supplemented with $10 \%$ fetal bovine serum without antibiotics.

Reagents. VP (SML0534) was purchased from Merck KGaA. For microscopy, MitoBright Green (MT06) and Hoechst-33342 solution (cat. no. 346-07951) were purchased from Dojindo Laboratories, Co., Ltd. Singlet Oxygen Sensor Green (cat. no. S36002) was purchased from Thermo Fisher Scientific, Inc.

Microscopic imaging. Cells were visualized with a fluorescence microscope (BZ-X710; Keyence Co.), using BZ-X filter GFP (OP-87763; Keyence Co.) and BZ-X filter DAPI (OP-87762; Keyence Co.). In addition, to visualize VP, a filter cube (OP-87767; Keyence Co.) was used with relevant excitation (405BP20) and fluorescence (RPE630LP) filters. Magnification of the objective lens was x10. For merging, noise reduction and signal intensity enhancement, BZ-analyzer (Keyence Co.) was used.
Photodynamic therapy protocol and proliferation assay. Cells were exposed to VP in serum-free medium, avoiding sunlight and room lights. VP treatment times were from $15 \mathrm{~min}$ to $1 \mathrm{~h}$. The cultures were irradiated with $660 \mathrm{~nm}$ light (LEDR-660DL; Optocode Co., Ltd.) at $2.5 \mathrm{~J} / \mathrm{cm}^{2}$ (11), and after $24 \mathrm{~h}$. Cell viability was measured using the MTS (3-(4,5-dimethylthiazol-2-yl)-5-(3-carboxymethoxyphenyl)-2(4-sulfophenyl)-2H-tetrazolium) assay (12). The MTS assay was performed by adding $20 \mu \mathrm{l}$ proliferation assay solution (G3580, CellTiter 96 ${ }^{\circledR}$ Aqueous One Solution Cell Proliferation Assay; Promega Co.) to $100 \mu \mathrm{l}$ culture medium, and after $1 \mathrm{~h}$, the absorbance at $490 \mathrm{~nm}$ was measured with a microplate reader (Vientonano; DS Pharma Biochemical Co., Ltd.) and the viability of the treated cells was compared to that of the untreated control cells.

Fluorescent staining of intracellular organelles. Cells were incubated with $0.1 \mu \mathrm{M}$ VP for $1 \mathrm{~h}$ at $37^{\circ} \mathrm{C}$, with avoiding sunlight and room lights, were washed twice with phosphate-buffered saline (PBS), and exposed to $0.1 \mu \mathrm{M}$ MitoBright Green for $10 \mathrm{~min}$ at $20-25^{\circ} \mathrm{C}$. The degree of staining was dependent on the membrane potential of the mitochondria, as the compound accumulated specifically in normal mitochondria after cell membrane permeation. Cells were washed again with PBS and imaged using a fluorescence microscope.

Singlet oxygen staining. Cells were incubated with $0.1 \mu \mathrm{M} \mathrm{VP}$ ( $1 \mathrm{~h}$ at $37^{\circ} \mathrm{C}$ with avoiding sunlight and room lights), washed twice with PBS, and exposed to $1 \mu \mathrm{M}$ Singlet Oxygen Sensor Green. This reagent emits a green fluorescent signal in the presence of S1 oxygen. Irradiation was performed at a wavelength of $660 \mathrm{~nm}$ at $2.5 \mathrm{~J} / \mathrm{cm}^{2}$ and after $2 \mathrm{~h}$, the cells were visualized using a fluorescent microscope.

Mitochondrial ATP analysis. Necrosis and mitochondrial ATP were evaluated using the Mitochondrial ToxGlo ${ }^{\text {TM }}$ Assay (G8000; Promega Co.). Briefly, $20 \mu \mathrm{l}$ cytotoxicity reagent was added to $100 \mu \mathrm{l}$ medium including cells, the cells were incubated for $30 \mathrm{~min}$ at $37^{\circ} \mathrm{C}$, and the fluorescence was measured at $485 \mathrm{~nm}_{\mathrm{Ex}} / 535 \mathrm{~nm}_{\mathrm{Em}}$. Subsequently, $100 \mu \mathrm{l}$ ATP detection reagent was added and the cells were incubated for $5 \mathrm{~min}$ at $20-25^{\circ} \mathrm{C}$. Fluorescence and luminescence were measured by multi detection mode plate reader (Infinite F500; Tecan Japan Co., Ltd.).

Detection of apoptosis. To detect apoptosis, Hoechst staining was performed. Cells were incubated with $0.5 \mu \mathrm{M}$ VP for $1 \mathrm{~h}$ at $37^{\circ} \mathrm{C}$, with avoiding sunlight and room lights. Subsequently, the cells were irradiated with LED with the power shown in each figure. After LED irradiation, the cells were incubated for $12 \mathrm{~h}$ at $37^{\circ} \mathrm{C}$, washed, and incubated with $1 \mu \mathrm{g} / \mathrm{ml}$ Hoechst-33342 solution for $15 \mathrm{~min}$ at $20-25^{\circ} \mathrm{C}$, with avoiding sunlight and room lights. The cells were then visualized using a fluorescence microscope.

Statistical analysis. All experiments were repeated at least 3 times. The Kolmogorov-Smirnov test was used to assess normal distribution. Differences between groups were analyzed using one-way analysis of variance test for normally distributed variables with post hoc Dunnet's test. The Kruskal-Wallis test 
Table I. $\mathrm{EC}_{50}$ values of VP.

\begin{tabular}{lcc}
\hline & \multicolumn{2}{c}{$\mathrm{EC}_{50}$ of VP $(\mu \mathrm{M})$} \\
\cline { 2 - 3 } Treatment time (min) & MKN45 & MKN74 \\
\hline 30 & 0.61 & 1.21 \\
60 & 0.32 & 0.80 \\
\hline
\end{tabular}

$\mathrm{EC}_{50}$, half maximal effective concentration; VP, verteporfin.

with post hoc Dunn's test was used for non-normally distributed variables. Data are expressed as mean \pm standard error and differences were considered statistically significant at $\mathrm{P}<0.05$.

\section{Results}

Induction of singlet oxygen and apoptosis. VP was localized to the mitochondria after uptake into GC cells (Fig. 1A) and irradiation generated S1 oxygen molecules (Fig. 1B). Furthermore, chromatin condensation and fragmentation, which are characteristic of apoptosis, were observed in GC cells (Fig. 1C), whereas the control cells (without VP-PDT) did not show apoptotic cell death after irradiation.

VP-PDT cytotoxicity on MKN45 and MKN74 cells. As the results of the proliferation assay reveal, the effect of VP-PDT $\left(2.5 \mathrm{~J} / \mathrm{cm}^{2}\right)$ on MKN45 and MKN74 cells was already apparent after 15 min of VP treatment (Fig. 2A and B). Treatment for $30 \mathrm{~min}$ and $1 \mathrm{~h}$ increased the effectiveness of the treatment (Fig. 2C-F, respectively). The $\mathrm{EC}_{50}$ values for $\mathrm{VP}$ are shown in Table I. Cell viability did not reach below $50 \%$ after $15 \mathrm{~min}$ of treatment (Fig. 2B). Furthermore, cell damage was not observed with LED irradiation $\left(3,5\right.$ and $10 \mathrm{~J} / \mathrm{cm}^{2}$; Fig. 3A) or VP treatment (1, 5 and $10 \mu \mathrm{M}$; Fig. 3B and $\mathrm{C})$ alone. VP-PDT reduced mitochondrial ATP, but not protease activity, indicating that VP-PDT exertded the effect through apoptosis (Fig. 3D).

\section{Discussion}

In the present study, VP-PDT induced apoptosis via the production of $\mathrm{S} 1$ oxygen molecules, reactive oxygen species, and by mitochondrial damage, as previously reported (13). Furthermore, although VP has been reported to inhibit yes-associated protein (YAP)-transcriptional enhanced associate domain (TEAD) and human retinoblastoma cells growth in vitro without light activation (14), VP alone did not show an antitumor effect in this study. As VP alone showed YAP inhibition at higher concentrations and longer times (data not shown), it is considered that only mitochondrial damage via reactive oxygen species was induced in this condition, not the effect of VP alone. Furthermore, comparing our study results with those of clinical (14) or in vitro (15) studies, the VP concentration used in PDT was approximately $1 / 10$ of that when used alone as a YAP-TEAD inhibitor. Therefore, VP-PDT is expected to have fewer side effects such as photosensitivity and less burden on patients. The possibility that VP-PDT, which is approved only for age-related macular degeneration, can be extended to
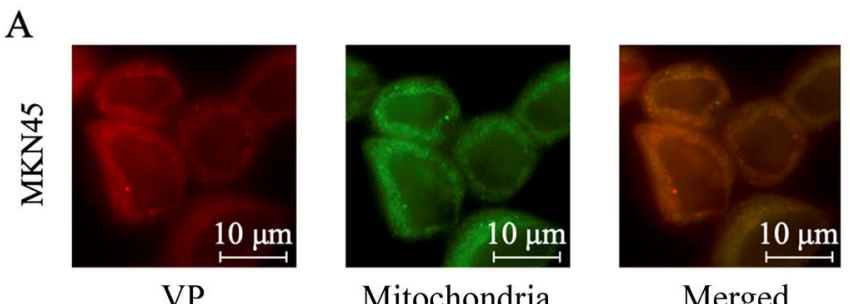

Mitochondria
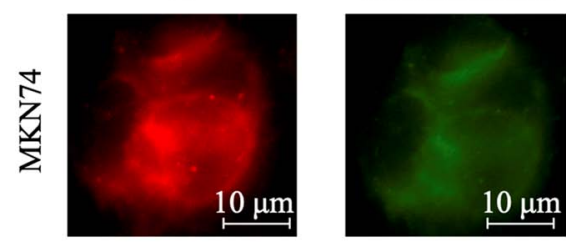

Merged
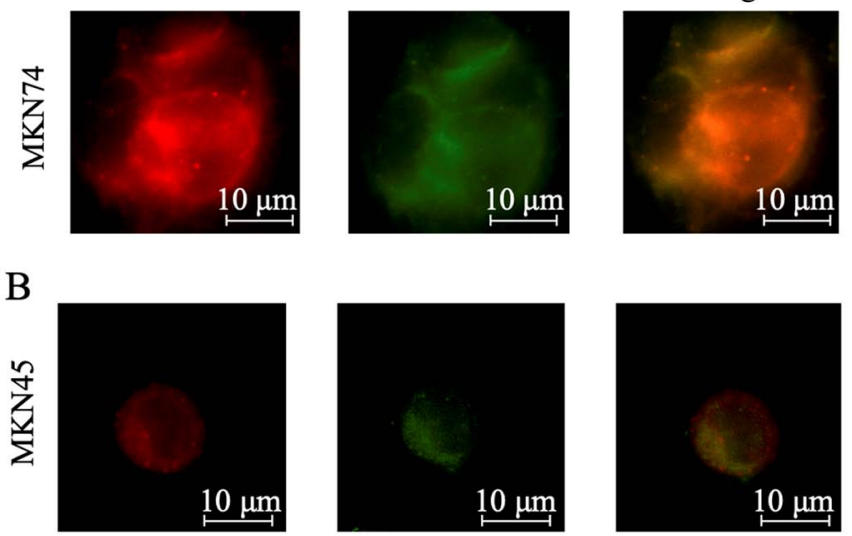

VP

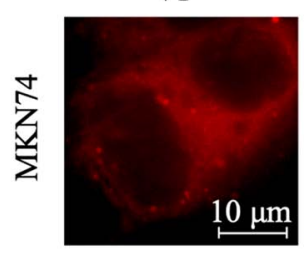

Singlet oxygen

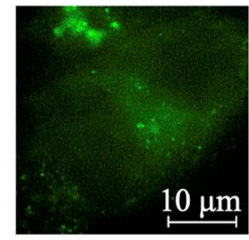

Merged
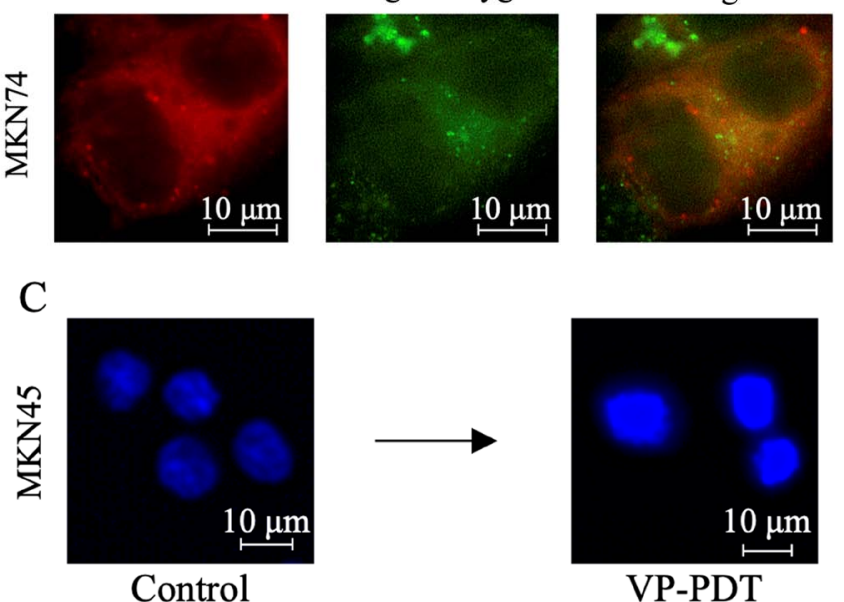

VP-PDT

Figure 1. Imaging of VP-PDT effect. (A) Uptake and intracellular localization of VP. Mitochondria and VP emitted green and red fluorescent light, respectively. Magnification of the objective lens was 10X. (B) Generation of singlet (S1) oxygen following VP-photodynamic therapy (PDT). S1 oxygen and VP emitted green and red fluorescence, respectively. Magnification of the objective lens was 10X. (C) Induction of apoptosis following VP-PDT. Condensation and fragmented chromatin emitted a stronger fluorescent signal than control cells by Hoechst staining. VP, verteporfin; PDT, photodynamic therapy.

GC treatment has also been shown (7). In addition, since VP is effective at lower concentration than TS concentration for local failure after chemoradiotherapy for esophageal cancer, high safety is expected in the treatment of GC.

As such, we demonstrated that VP-PDT is effective for inhibition of proliferation on MKN45 and MKN74 GC cell lines. Of note, it has been reported that the intracellular uptake of VP is related to the LDL receptor (16). In a previous study, we reported that the LDL receptor has a role in the mode-of-action of TS-PDT. More specifically, the expression of the LDL receptor was different between MKN45 and MKN74 GC cells; the latter demonstrated a lower expression of the LDL receptor, and was thus resistant to TS-PDT (17). However, MKN74 cells showed no resistance to VP-PDT. A plausible reason for this difference may be the involvement 
A

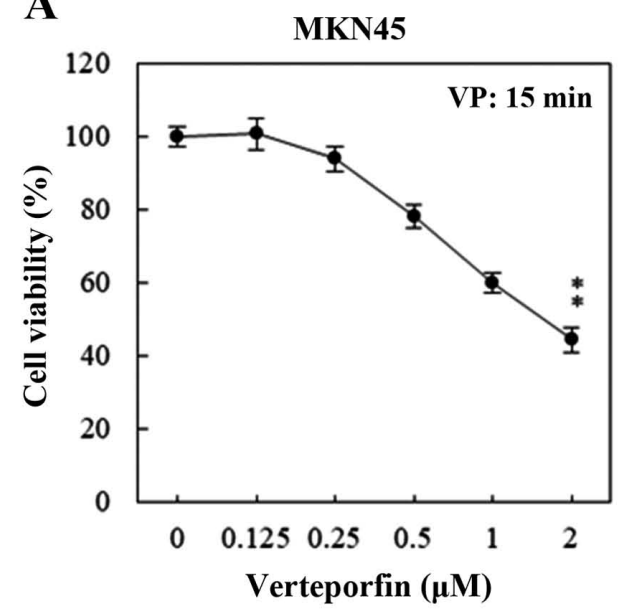

C

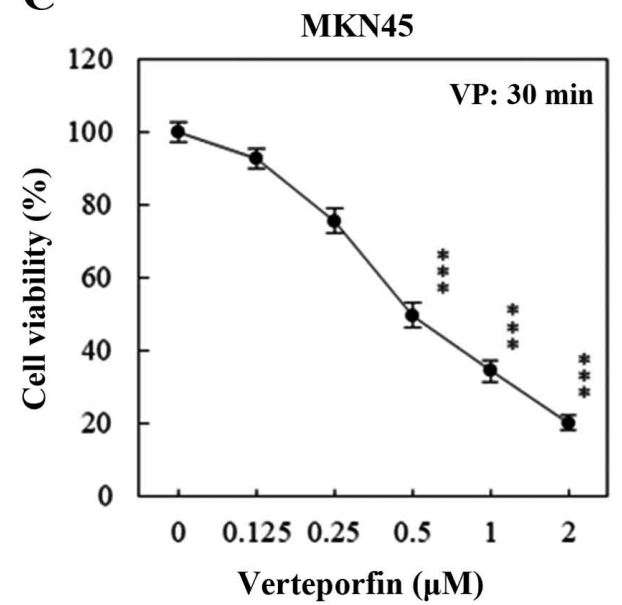

$\mathbf{E}$

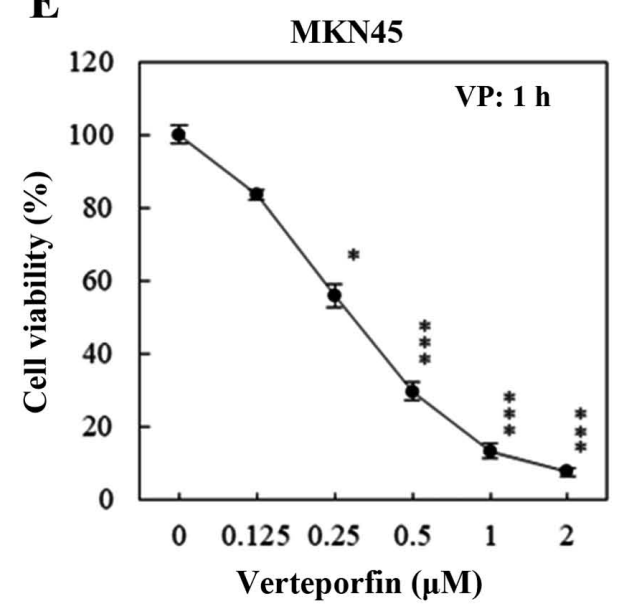

B

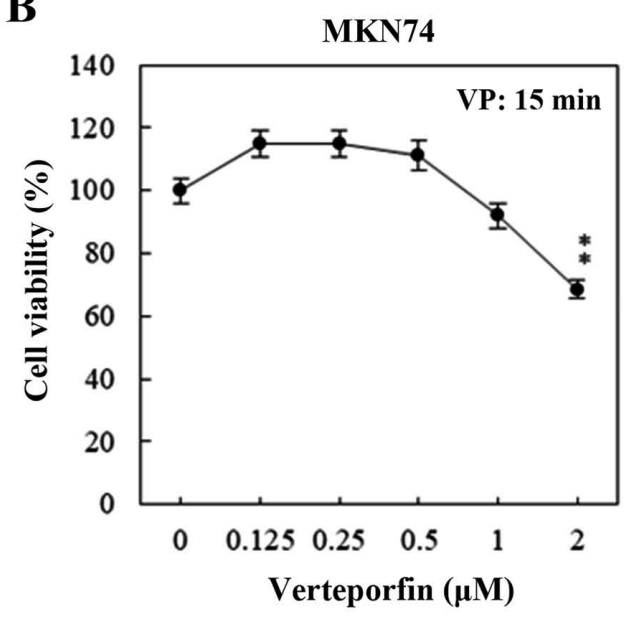

D

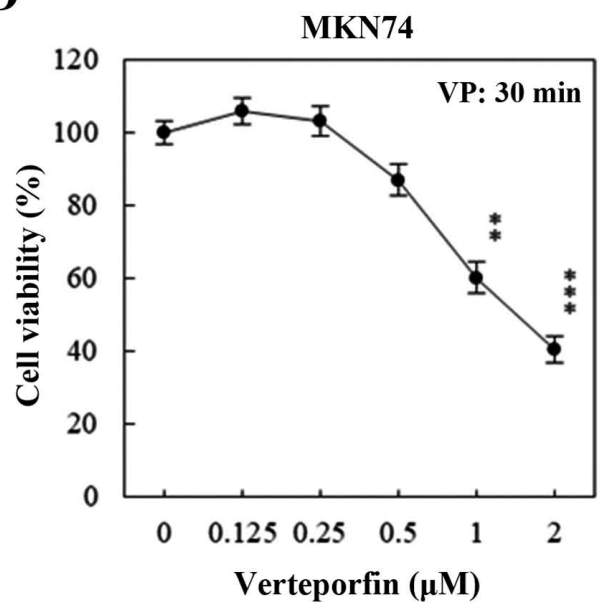

$\mathbf{F}$

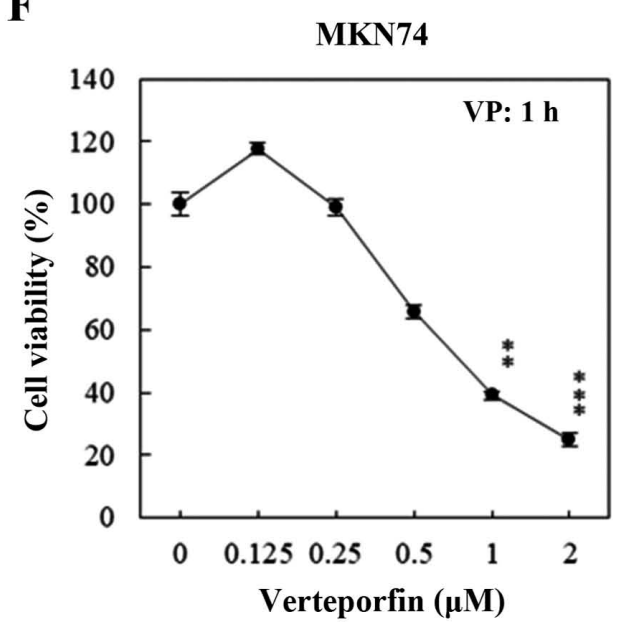

Figure 2. Photodynamic therapy (PDT) efficacy evaluated by proliferation assay. Cell viability was measured one day after irradiation with a 660 nm and $2.5 \mathrm{~J} / \mathrm{cm}^{2}$ LED. Verteporfin (VP)-treatment time was (A and B) $15 \mathrm{~min}$, (C and D) $30 \mathrm{~min}$, and (E and F) $1 \mathrm{~h}$. Asterisks highlight significant changes (* $<<0.05$, $\left.{ }^{* *} \mathrm{P}<0.01,{ }^{* * *} \mathrm{P}<0.001\right)$ and error bars indicate standard error.

of non-LDL receptors in the uptake of VP. Alternatively, the uptake of very small amounts of VP via the low-abundance LDL receptor may explain the effects that we observed. Nonetheless, testing this hypothesis was beyond the scope of the current study, which focused on evaluating the efficacy of VP-PDT in an in vitro model for its potential future clinical applications. In addition, because a non-liposomal reagent was used in this study, we expect that a liposomal VP (Visudyne; Novartis Pharma, Co.) would show stronger anti-tumor effects on GC cells with a low expression of the LDL receptors. More specifically, here the uptake might be primarily via endocytosis, rather than via the LDL receptor. 
$\mathbf{A}$

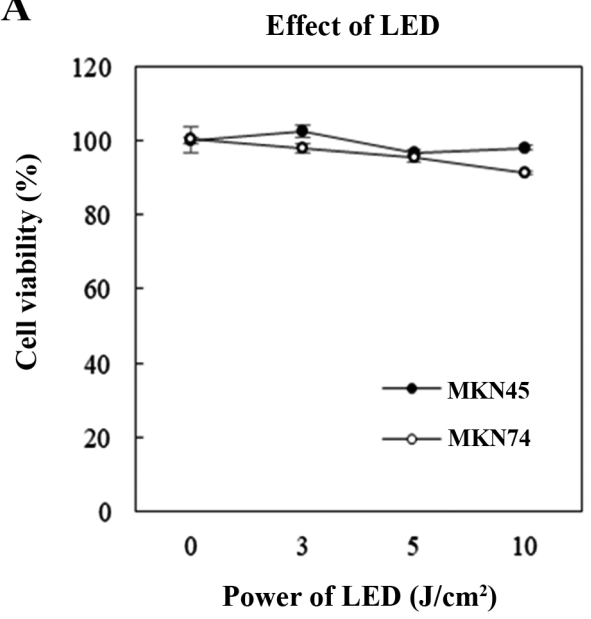

C

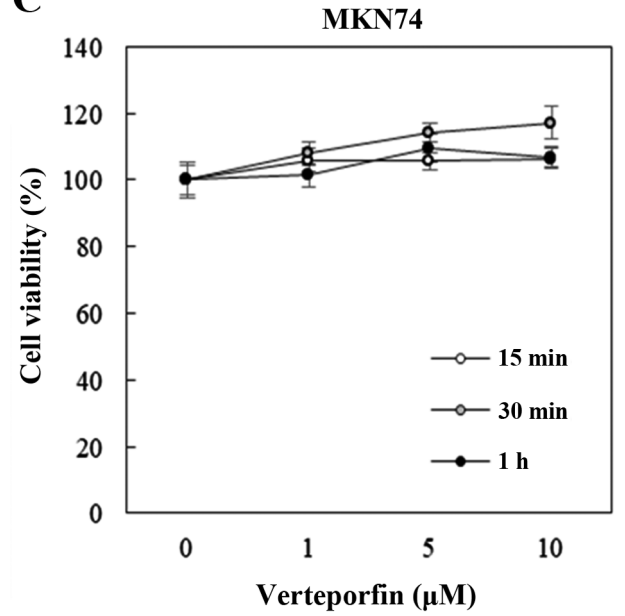

B

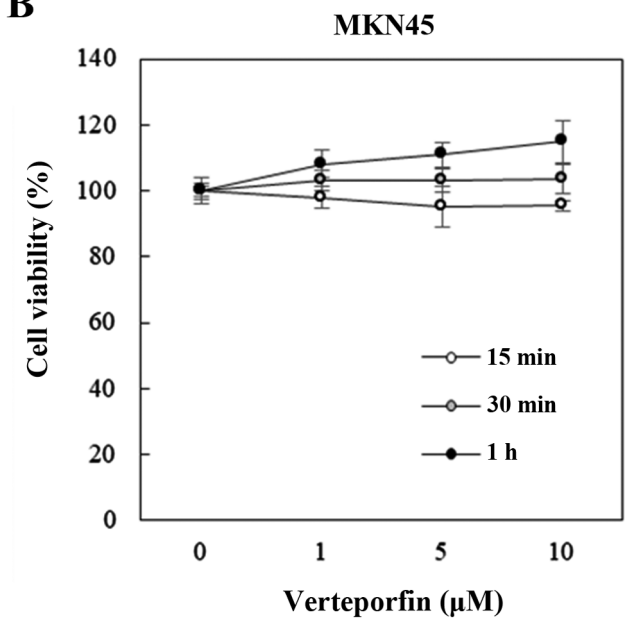

D

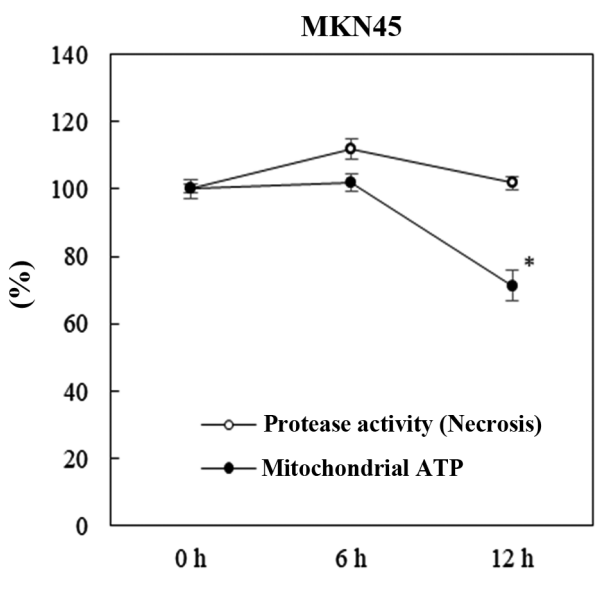

Figure 3. Cell viabilities in cells treated with LED alone and VP alone. (A) Effect of LED only in MKN45 and MKN74. LED was irradiated at 3, 5 and $10 \mathrm{~J} / \mathrm{cm}^{2}$. There was no significant change in cell viabilities by light irradiation. Effect of VP without light irradiation in (B) MKN45 and (C) MKN74. Cells were treated with VP at concentrations of 1,5 and $10 \mu \mathrm{M}$ for 15,30 and $60 \mathrm{~min}$. No significant difference was observed following treatment with VP. (D) Protease activity and mitochondrial ATP were measured in MKN45 cells treated by VP with light irradiation. The combination of VP and LED reduced mitochondrial ATP but not protease activity, indicating that VP-PDT exerts the effect through apoptosis. Asterisk highlights significant change $($ P $<0.05)$ and error bars depict standard error. VP, verteporfin; PDT, photodynamic therapy.

Human pancreatic duct epithelial cells and normal rat gastric epithelial cells were used as control cells. However, the effect of VP-PDT on these cells was similar to that on MKN45 and MKN74 cells. Additionally, the $\mathrm{EC}_{50}$ value of VP-PDT $\left(690 \mathrm{~nm}\right.$ and $\left.10 \mathrm{~J} / \mathrm{cm}^{2}\right)$ for human vascular smooth cell was $0.01785 \mu \mathrm{M}$ (18). The power of LED of that study was reduced. Therefore, we presume that the results are similar between the current study and that study. However, the control cells we used in the present study were modified for cell culture; thus, the results of our data may not be directly applied to healthy body. This is a limitation of this study using these control cells.

The $\mathrm{EC}_{50}$ calculated for VP-PDT in this study was approximately $2 / 3$ th to $1 / 6$ th of the maximun blood concentration $(1.84 \mu \mathrm{M})$ used to treat aging macular degeneration (Visudyne). This $\mathrm{EC}_{50}$ was lower than that of TS-PDT, as previously reported (17). In detail, the $\mathrm{EC}_{50}$ of TS-PDT was over $20 \mu \mathrm{M}$ and treatment time of TS required at least $4 \mathrm{~h}$. Furthermore, VP-PDT was effective on MKN74 cells that demonstrated resistance against TS-PDT (17). Additionally, the $\mathrm{EC}_{50}$ of VP in this study was approximately identical to the effective VP-PDT concentration that was used against gemcitabine-resistant pancreatic cancer cells (13). Clinical trials using VP-PDT to treat pancreatic cancer have already been conducted, and the efficacy of the method has already been demonstrated (8). As such, we predict that the same dose of VP-PDT could be used safely against GC in the clinical setting. However, we used LED light with a wavelength of $660 \mathrm{~nm}$, which is covered by the broad absorption band of VP; it has been reported that the peak absorption coefficient of VP is $689 \mathrm{~nm}$ (19). Therefore, a more pronounced effect of VP-PDT on GC cell lines is expected when LEDs with a wavelength closer to $689 \mathrm{~nm}$ are used. However, we used $660 \mathrm{~nm}$ LED light because of lack of necessary equipment. Further research currently in progress has focused on the development of an experimental LED device, capable of illumination at $689 \mathrm{~nm}$, for use in combination with VP, which may lead to further improvements with regard to the depth of invasion. It is also necessary to consider the optimal LED wavelength. Furthermore, it has not been confirmed whether similar effects can be obtained in animals and humans.

Limitations of this study should also be considered. First, although the peak absorption coefficient of VP was $689 \mathrm{~nm}$, use 
of LED at $689 \mathrm{~nm}$ for irradiation could not be carried out owing to absence of equipment. However, we observed that irradiation with LED at even $660 \mathrm{~nm}$ inhibited GC cell proliferation. Second, we revealed inhibition of proliferation only in vitro. Therefore, in future, detailed clinical or in vivo experiments should be performed to support the arguments presented in this study. Furthermore, the cell lines used in the evaluation of VP-PDT on normal cells are derived from different organs or different species, constituting another limitation of this study.

In conclusion, we have demonstrated that VP-PDT is an effective strategy for inhibition of proliferation on GC cells, and anticipate that in the future, VP will be implemented in the clinical treatment of GC with PDT.

\section{Acknowledgements}

Not applicable.

\section{Funding}

No funding was received.

\section{Availability of data and materials}

All data generated or analyzed during this study are included in this published article.

\section{Authors' contributions}

YM and TK acquired data, analyzed and interpreted the data, and drafted the manuscript. TSu and TT also analyzed and interpreted the data. HKi, TSa, TH, RT, ME and HKu assisted in acquiring the data. YI and $\mathrm{KK}$ made contributions to the conception and design of the study. HI made substantial contributions to the conception and design of the study and drafted the manuscript. All authors read and approved the final manuscript.

\section{Ethics approval and consent to participate}

Not applicable.

\section{Patient consent for publication}

Not applicable.

\section{Competing interests}

The authors declare that they have no competing interests.

\section{References}

1. Siegel RL, Miller KD and Jemal A: Cancer statistics, 2017. CA Cancer J Clin 67: 7-30, 2017.

2. Isomoto H, Shikuwa S, Yamaguchi N, Fukuda E, Ikeda K, Nishiyama H, Ohnita K, Mizuta Y, Shiozawa J and Kohno S: Endoscopic submucosal dissection for early gastric cancer: A large-scale feasibility study. Gut 58: 331-336, 2009.
3. Oinuma T, Nakamura T and Nishiwaki Y: Report on the national survey of photodynamic therapy (PDT) for gastric cancer in Japan (a secondary publication). Laser Ther 25: 87-98, 2016.

4. Nakamura $T$ and Oinuma T: Usefulness of photodynamic diagnosis and therapy using talaporfin sodium for an advanced-aged patient with inoperable gastric cancer (a secondary publication). Laser Ther 23: 201-210, 2014.

5. Ethirajan M, Chen Y, Joshi P and Pandey RK: The role of porphyrin chemistry in tumor imaging and photodynamic therapy. Chem Soc Rev 40: 340-362, 2011.

6. Brown SB and Melish KJ: Verteporfin: A milestone in opthalmology and photodynamic therapy. Expert Opin Pharmacother 2: 351-361, 2001.

7. Messmer KJ and Abel SR: Verteporfin for age-related macular degeneration. Ann Pharmacother 35: 1593-1598, 2001.

8. Huggett MT, Jermyn M, Gillams A, Illing R, Mosse S, Novelli M, Kent E, Bown SG, Hasan T, Pogue BW and Pereira SP: Phase I/II study of verteporfin photodynamic therapy in locally advanced pancreatic cancer. Br J Cancer 110: 1698-1704, 2014.

9. Park S, Hong SP, Oh TY, Bang S, Chung JB and Song SY: Paclitaxel augments cytotoxic effect of photodynamic therapy using verteporfin in gastric and bile duct cancer cells. Photochem Photobiol Sci 7: 769-74, 2008.

10. Shimokawa O, Matsui H, Nagano Y, Kaneko $T$, Shibahara T, Nakahara A, Hyodo I, Yanaka A, Majima HJ, Nakamura Y and Matsuzaki Y: Neoplastic transformation and induction of $\mathrm{H}+, \mathrm{K}+$-adenosine triphosphatase by $\mathrm{N}$-methyl-N'-nitro-N-nitrosoguanidine in the gastric epithelial RGM-1 cell line. In Vitro Cell Dev Biol Anim 44: 26-30, 2008.

11. Nanashima A, Isomoto $\mathrm{H}$, Abo T, Nonaka T, Morisaki T, Arai J, Takagi K, Ohnita K, Shoji H, Urabe S, et al: How to access photodynamic therapy for bile duct carcinoma. Ann Transl Med 2: 23, 2014.

12. Yang MY, Chang CJ and Chen LY: Blue light induced reactive oxygen species from flavin mononucleotide and flavin adenine dinucleotide on lethality of HeLa cells. J Photochem Photobiol 173: 325-332, 2017.

13. Celli JP, Solban N, Liang A, Pereira SP and Hasan T: Verteporfin-based photodynamic therapy overcomes gemcitabine insensitivity in a panel of pancreatic cancer cell lines. Lasers Surg Med 43: 565-574, 2011.

14. Katarzyna B, Moujahed A, Marmalidou A, Horste MM zu, Cichy J, Miller JW, Gragoudas E and Vavvas DG: The clinically used photosensitizer verteporfin (VP) inhibits YAP-TEAD and human retinoblastoma cell growth in vitro without light activation. Exp Eye Res 124: 67-73, 2014.

15. Kang MH, Jeong GS, Smoot DT, Ashktorab H, Hwang CM, Kim BS, Kim HS and Park YY: Verteporfin inhibits gastric cancer cell growth by suppressing adhesion molecule FAT1. Oncotarget 8: 98887-98897, 2017.

16. Newman DK: Photodynamic therapy: Current role in the treatment of chorioretinal conditions. Eye 30: 202-210, 2016

17. Kanda T, Sugihara T, Takata T, Mae Y, Kinoshita H, Sakaguchi T, Hasegawa T, Kurumi H, Ikebuchi Y, Murakami T and Isomoto H: Low-density lipoprotein receptor expression is involved in the beneficial effect of photodynamic therapy using talaporfin sodium on gastric cancer cells. Oncol Lett 17: 3261-3266, 2019.

18. Labow RS, Higginson LA, Irvine J, Keaney M, Masters RG, Marquis JF, Meek E, Mussivand T, Walley VM, Logan P, et al: Assessment of the cytotoxicity of the photosensitizing drug BPD verteporfin using human vascular smooth muscle cells in culture. J Cardiovasc Pharmacol 26: 729-736, 1995.

19. Houle JM and Strong HA: Clinical pharmacokinetics of verteporfin. J Clin Pharmacol 42: 547-557, 2002. 